\title{
Using Context Clues in Sentences by Cambridge IGCSE Students to Understand the Nonliteral Meanings of Words
}

\author{
Dr. Samir Al Jumaily ${ }^{1}$ \\ ${ }^{1}$ Postgraduate Department, International Colleges of Islamic Science, London, United Kingdom
}

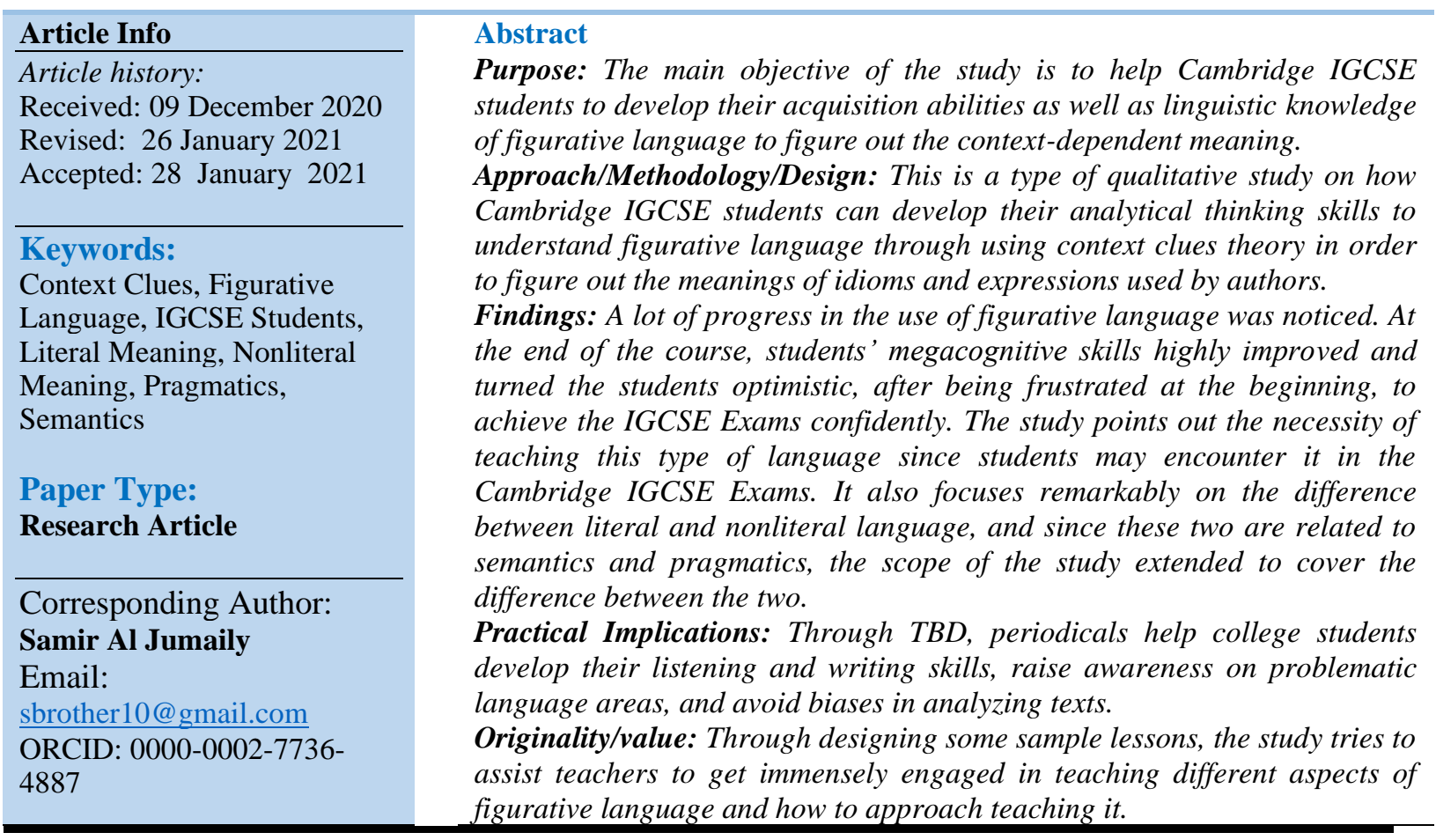

\section{Introduction}

IGCSE students of Cambridge Schools are required to deal with two papers in the exam, namely paper 1 which is related to reading and paper 2 which goes to writing. Thus, the curriculum of the IGCSE Cambridge Schools overwhelmingly focuses on these two papers. When students do the reading task, they must figure out and analyse the literary devices alongside the type of language used by the writer, whereas in doing paper 2 (writing), students must consider and take on board these literary devices. Consequently, since these students were not native speakers and learning English as a first language according to the IGCSE program/curriculum, they were expected to face difficulties related to their analytical thinking and writing skills. Being a teacher of this program, the researcher noticed that the majority of the students were struggling to achieve these two papers efficiently. Accordingly, the researcher took the burden to find ways to help students as well as teachers to overcome these difficulties through organizing various reading and writing activities as well as lessons for teachers wherein the figurative language was used. Students' Textbooks, Workbooks, 
computers, internet and videos were the major tools used. It is necessary to mention that students were grade 9 of both sexes; male and female.

The core issue of this qualitative study is figurative language which represents patterns of thought mainly used by authors and students are required to figure it out in order to comprehend and analyse texts. This study was designed and devoted to assist IGCSE students following the procedure below:

- Providing a brief account of Cambridge IGCSE curriculum which focuses on paper 1 (reading) and paper 2 (writing) in which figurative language used/required.

- Providing linguistic background of literal and nonliteral meanings as well as the difference between the two.

- Studying the relationship between language and meaning which leads to study the difference between what is conventionally called semantics and pragmatics. Thus, these two fields discussed fully relying on various perspectives of notorious linguists. In order to ensure reliability and credibility, various references and sources consulted.

- Discussing how to develop Cambridge IGCSE students' comprehension, analysis, discussion, and writing skills mainly through practising metacognitive task.

- Demonstrate a brief guidance for IGCSE students on how to write an article.

- Suggesting some especially tailored lessons for students as well as teachers to develop students' analytical thinking and writing skills.

○ The study ends with making suggestions and recommendation for future studies.

Although the nature of Cambridge IGCSE Schools Curriculum makes the opportunity available for students to respond with understanding to a wide range of interesting reading texts and passages (paper 1), unfortunately they were facing difficulties to understand idioms used figuratively since they were not familiar with those idioms having context-dependent meaning. Since these male and female students are not native speakers while learning English as a first language, and their parents don't use English at home, they could not acquire the nonliteral idioms usually used by native speakers. It is natural and common that native speaker children grow up learning these idioms and expressions from their parents or friends due to the home or community linguistic environment. Ortony (1984) confirms that "very young children can understand some forms of figurative language (p.453). Given that students encounter figurative language in both oral and written expressions every day, the introduction figurative language instruction must start as early as possible". The non-native speaker children miss this opportunity as above mentioned. According to Grave et al. (2007), these students don't "come to school with a language deficit", but "they come with a lack of knowledge of the particular language that is used in the schools" (p.400). When given assignments to interpret figurative language, which is based on schematic experiences completely different from their cultural backgrounds, the students may be unsuccessful. The challenges were evident and the focus for instructional design was necessary and must drive teachers to consider building up background experience as part of the learning process. According to Palmer and Brooks (2004) "to begin the process of comprehending a figurative phrase, the student must be familiar with the cultural values and beliefs that form the context of the phrase (p.373). Next, having knowledge of the 
different forms of figurative language enables the student to recognize more readily nonliteral text. Finally, knowing the context in which the figurative phrase is being used increases the student's ability to interpret it accurately".

Hence, it was planned that students must get engaged with so many texts and passages following the context clues method to demonstrate their reading comprehension abilities in order to skilfully spot the keywords and technique used to do the analysis process as well as using them in paper 2 to inform and inspire their own writing for a variety of purposes and audiences. Part of the technique used by writers, they usually use figurative language which is nonliteral and immensely available through using literary techniques such as metaphor, simile, allusion, diction, euphemism, dyphemism, personification, analogy, puns, allegory, oxymoron, paradox, alliteration, assonance, hyperbole, consonance, etc., to express their purposes, and accordingly students should work likewise to demonstrate accurate and effective use of this language in composition writing. Therefore, their writings have to include words and phrases of literal and nonliteral meanings. For example, in writing poetry, poets mainly use nonliteral language in order to make their audience highly engaged. On the contrary, writers use literal language for straightforward documents when their major purpose is to inform. Accordingly, students must work hard to develop their literary analytical thinking skills as well as having the ability to use context clues in addition to their own knowledge and experience to help themselves to determine whether the meaning of a word or a phrase is literal or nonliteral.

Context clues are bits of information such as signs and indications usually available in sentences, paragraphs and texts that can be used by readers to decipher the meaning of new words, idioms and expressions which readers are not familiar with. It is extremely crucial for Cambridge IGCSE students to develop their comprehension and analytical thinking skills through this technique. Realizing and understanding the meaning of words through their use in a context is the most effective or functional method to boost and enrich students' vocabulary knowledge, because dictionaries provide only the formal basic linguistic lexical meaning. Students must be aware that words may have various meanings, especially when they are grouped with other words to form phrases such as idioms and other expressions. Therefore, they are required to be cognitively aware of the linguistic surrounding environment in which words are used to well recognize, decipher and understand the suitable contextual meaning. But, in case the context clues propose a variety of possible meanings due to the feeling that the nearby words are commonplace, the students must look them up in their dictionaries. Sometimes, punctuation plays a major role in deciding the meaning of words, mainly through the use of commas, dashes and parentheses, e.g. John, says Peter, killed James. This sentence is fuzzy without commas, and it may indicate that John or Peter either is the killer. To summarize, there are various types of context clues students can practice to figure out the meaning of phrases; idioms and expressions such as examples, restatements, cause/effect relationship, comparison, synonyms and antonyms.

The following are some examples related to context clue theory:

1. Due to having the entire building on fire, the air was filled with smoke (literal), 
2. After the boy ran for a long time, he felt his stomach on fire (nonliteral).

In the $1^{\text {st }}$ sentence, "on fire" used literally indicating that the building was entirely in flames and burning down. The context clue shows that the air filled with smoke makes the audience understands that the meaning is literal, whereas the $2^{\text {nd }}$ sentence contains a nonliteral meaning. The boy's stomach felt like it was burning. The writer uses "on fire" to better describe the pain the boy felt. Literal meaning tells exactly what it is meant, while non-literal language expresses a different meaning from the normal. It has been found essential to elaborate and provide the reader with a brief account about the background of the two meanings.

\section{Literal and nonliteral meaning}

Semantics, which is a subfield of linguistics; the scientific study of language, is the study of meaning that deals with two types: literal and nonliteral meaning. Semantically, there are linguistic meaning and speaking meaning which differ from each other according to the speaker's intention whether speaking literally or non-literally. The distinction between the two can be realized through the following example: suppose that you are arguing with someone and in a moment he/she says, "The door is right behind you!" You would supposedly and immediately understand from this utterance the speaker means that you are to leave- although the speaker's actual words indicate nothing more than the location of the door. This illustrates how a speaker can use an expression to mean something quite different from what his or her words mean. Gray (1984) confirms that "Literal meaning is its most exact, precise and limited meaning, without reference to secondary or symbolic or metaphorical meaning".

"In general, the linguistic meaning of an expression is simply the meaning or meanings of that expression in the language. In contrast, the speaker meaning can differ from the linguistic meaning, depending on whether the speaker is speaking literally or non-literally. When we speak literally, we mean what our words mean, and in this case there is no important difference between speaker meaning and linguistic meaning. But when we speak non-literally, we mean something different from what our words mean" (Akmajian et al, 2010, p.227). A literal meaning of a word usually refers to the exact textbook definition or as it appears in a dictionary without embellishment, while non-literal meaning shows an exaggerated definition which is often available with figurative language. Researchers believe that expressions or utterances containing literal meaning may be easily realized and understood since they have the real precise meaning beyond making any association with something else or symbolic meaning. Literal meaning is mainly based on the actual words or the real means not using figurative or symbolic associations (Holman \& Harmon, 1986). When someone uses literal language, there is no hidden meaning in his/her words. In the literal meaning there is no misunderstanding or misinterpretation between the speaker and listener at all.

People regularly use idioms and expressions that have nonliteral meaning. So, when they are using such idioms and expressions, their purpose or intension to mean something different from that which is usually meant. It is believed that when the speaker speaks something like words or sentences, which implies the different meaning from its really mean, that is the time as nonliteral meaning. Contrary to literal meaning, sentences and expressions spoken by someone 
may contain hidden meaning alongside the lexical meaning. Daily, we may face many nonliteral meanings whether in speech, literature, play, words, etc. It is believed that the nonliteral meaning is always needed for making our sentences sound more effective, beautiful and artistic and for other reason it might be the best way to substitute any offensive word or replacement for unpleasant words for some people. For example, people may use the expression "passed away" instead of "died". This is called euphemism. Linguistically, it is known that an idiom is a phrase that has a meaning which is different than that a single word has. For example, it is easy to guess the meaning of the word "leg", but when it is grouped with other words to comprise an idiom, it expresses a new meaning. See the following idioms wherein "leg" is used to express meanings that are different from the basic meaning available in dictionaries:

- pulling your legs: joking

- doesn't have a leg to stand on: can't prove something

- break a leg: good luck

- kick a man when he is down: to attack someone at his/her weakest moment

- shake a leg: hurry up

- cost an arm and a leg: cost a lot of money

- get sea leg: used to standing and walking on boats

- tail between his leg: having been scolded or told off

- have a hollow leg: the ability to eat a lot and not gain weight

- put pants on one leg at a time: just like everyone else

- one last legs: near the end of life or useless

- talk the hind legs off a donkey: talks a lot

The main characteristic in social communication is how far the receiver (hearer) is capable to figure out whether the speaker is expressing himself/herself literally or nonliterally. Further, the process might be more complicated when the meanings of words can vary on the individual level within the same dialect. 'For example, the word 'infer' seems to have different meanings for different speakers. For some speakers, it has roughly the same meaning as 'conclude', as in 'I infer from what you say that you are sick'. For other speakers, it has roughly the same meaning as imply, as in 'He inferred that he was fed up with us'. The language of a particular individual is referred to as that person's idiolect, and it is clear that the idiolect meaning of a word can differ from one person to another (even among people who can be said to speak the same dialect)" (Akmajian et al. 2010, p. 227). The following tree diagram shows the varieties of meaning:

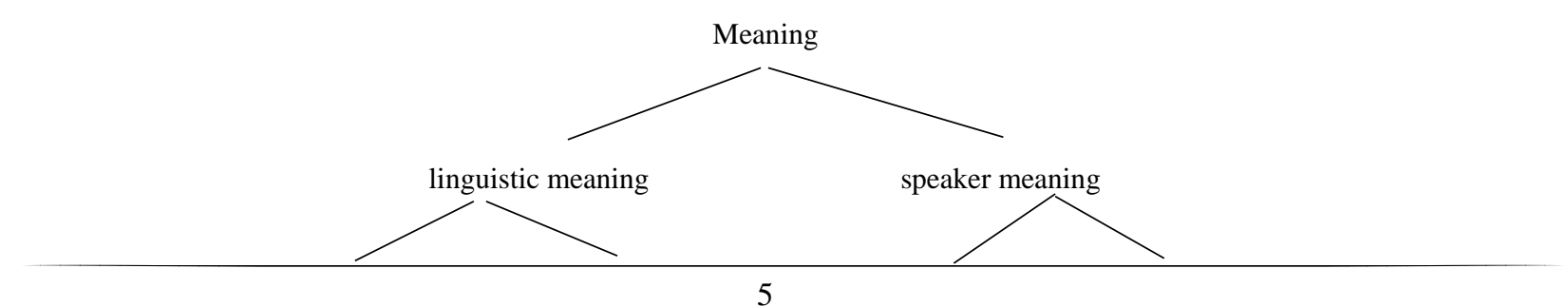

Copyright (C) 2021, Middle Eastern Journal of Research in Education and Social Sciences (MEJRESS), Under a Creative Commons Attribution 4.0 


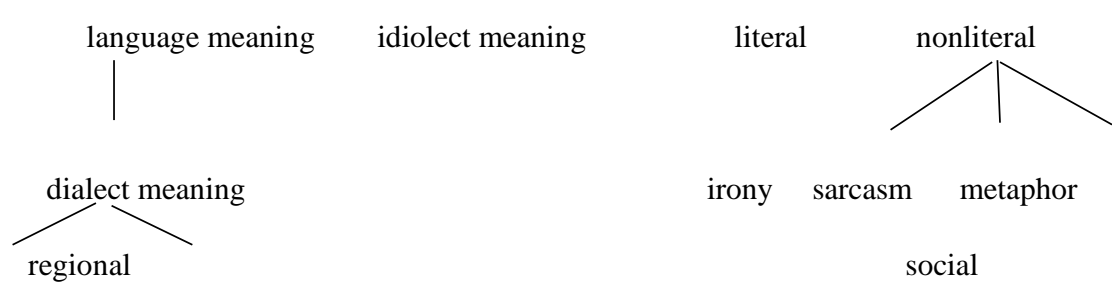

Therefore, authors, in order to be more effective as well as helping their audience to better understand what they are talking about, they often use nonliteral language. Through this use of imagery language, IGCSE students can develop their cognitive and analysis skills to get a better mental picture of what authors are walking into. One may ask 'why it is important to incorporate direct or explicit instruction in figurative language for ESL/EFL learners', the answer is that a lot of words and phrases can express both literal and nonliteral meanings.

Literal language consists of simple words and phrases that are usually precise. There is absolutely no use of confusing words in literal language. They express exactly what the writer is trying to portray. These words and phrases can be interpreted at first sight without any difficulties. In contrast, non-literal language tends to be more complex. Understanding their meanings can take a little more time. In short, they are not straightforward at all. Writings with non-literal language can be identified by the use of metaphors, similes, idioms personifications, etc. (https://www.englishworksheetsland.com/grade3/22literal.html?)

Tompkins (2002) illustrates that "literal meanings are the explicit, dictionary meanings, and figurative meanings are metaphorical or use figures of speech" (p.233). According to CarterisBlack (2002) "there is an increasing interest in the use of figurative language partly because of the growing awareness of such phenomena as metaphor and figurative idioms in everyday language" (p.104). Thus, Nippold \& Taylor (2002) assure that "those students who are not able to interpret figurative language will most probably fail to comprehend oral or written messages containing such language (p.384). As texts become more challenging across grades and the frequency of figurative language usage increases, the problem of comprehension potentially becomes more serious; therefore, children in the early grades must learn how to identity and interpret less complex figures of speech so that they can interpret more complex forms effectively as adolescents". So, IGCSE teachers are required to get engaged with and highly consider the use of nonliteral/figurative language described by personification, hyperbole, metaphor, simile, litotes, euphemism, synecdoche, symbol, paradox, understatement, alliteration, assonance, allegory, apostrophe, puns, and irony (Lauren \& Bernanrd, 1997, p.260).

When we study the relationship between language and meaning, we really study the difference between what traditionally called semantics and pragmatics. Linguists often describe and differentiate these two aspects through using the terms literal and nonliteral.

\section{Semantics and pragmatics}


Crystal (1987) considers semantics as "a major branch of linguistics devoted to the study of MEANING in LANGUAGE"(p.273). He adds "The term is also used in philosophy and logic, but not with the same range of meaning or emphasis in linguistics", whereas he (1987) describes pragmatics saying that "this term is traditionally used to label one of three major divisions of SEMIOTICS (along with SEMANTICS and SYNTACTICS)” (p.240). He further illustrates that "In modern LINGUISTICS, it has come to be applied to the study of LANGUAGE from the point of view of the users, especially of the choices they make, the CONSTRAINTS they encounter in using language in social interaction, and the effects their use of language has on other participants in an act of communication". The Random House Dictionary of English Language (1983) defines semantics as "the study of meaning" as well as "linguistic development by classifying and examining changes in meaning and form", whereas pragmatics is a "branch of semiotic dealing with the casual and other relations between words, expressions, or symbols and their users" (p.1128). The former (semantics) is also "called significs; the branch of semiotic dealing with the relations between signs and what they denote" (p.1296).Lyons (1987) proposed a differentiating between semantics and pragmatics saying "semantics deals with literal, and pragmatics with non-literal meaning"( p. 157). Likewise, Kadmon (2001) mentions “... I think that roughly, semantics only covers 'literal meaning' (p.3). Pragmatics has to do with language use, and with "going beyond the literal meaning." For Recanati (2004), the division between the two is as follows: "Semantics deals with the literal meaning of words and sentences as determined by the rules of the language, while pragmatics deals with what the users of the language mean by their utterances of words and sentences"(p.3).Cole (1981) used two other terms referring to literal and nonliteral meaning when saying "semantics is involved in the determination of conventional (or literal) meaning[...]', whereas pragmatics is concerned with ' $[\ldots .$.$] the determination of nonconventional$ (or nonliteral) meaning"(p.xi). Lyons (1987) agrees with Code when he says "semantics has to do with conventional, and pragmatics with the non-conventional, aspects of meaning" (p. 157). He goes farther to report that semantics deals with context-independent, and pragmatics with context-dependent meaning. Kats (1977) in his turn focuses on the notion of the "anonymous letter situation to characterise the kind of meaning captured 'draw the theoretical line between semantic interpretation and pragmatic interpretation by taking the semantic component to properly represent only those aspects of the meaning of the sentence that an ideal speakerhearer of the language would know in an anonymous letter situation, ... [where there is] no clue whatever about the motive, circumstances of transmission, or any other factor relevant to understanding the sentence on the basis of its context of utterance"(p.14). Crystal (1987), once more, defines pragmatics saying "Pragmatics studies the factors that govern our choice of language in social interaction and the effects of our choice on others"(p.120).

The two linguistic terms, literal and nonliteral meanings are related to a number of dichotomies available in the characterization of semantics and pragmatics. Consequently, these systems are often dubbed and designated to the differentiation between conventional and nonconventional meaning. So, this system shows harmony, on one hand, between literal, conventional and context-independent meaning, and nonliteral, nonconventional and contextdependent meaning on the other. Bach (2001a, p.249) assures that all of this is related to the two notions, semantics and pragmatics distinction in which "Words do not have nonliteral 
meanings [...], but they can be used in nonliteral ways. [...] In familiar cases, such as metaphor and metonymy, particular expressions are used nonliterally. [...] But there is a different phenomenon which I call "sentence nonliterality," [...] Here a whole sentence is used nonliterally, without any of its constituent expressions being so used."

According to the theory of sentence meaning and formal pragmatics, linguists, philosophers and logicians certain that in formal sentence, speaker meaning is minimized to sentence meaning, in the sense a receiver (hearer) immediately assumes that speakers only mean what it is said, but in daily conversations, the speaker's meaning often differs from the sentence meaning. To Jenny Thomas (1995, p.224), "pragmatics is one in which several different disciplines such as psychology, anthropology, social theory and sociolinguistics meet. The combination of different viewpoints has proved to be very fruitful as it has resulted in new ways of thinking about and accounting for language". He highly believes that Austin is the father of pragmatics, in addition to some other philosophers of language such as Grice, Searle, Moore, Russell and Wittgenstein. To summarize, pragmatics is the study of the practical aspects of human action and thought as well as being the study of the use of linguistic signs, words and sentences, in actual situations. It outlines the study of meaning in the interactional context. It looks beyond the literal meaning of an utterance and considers how meaning is constructed as well as focusing on implied meanings. It considers language as an instrument of interaction, what people mean when they use language and how we communicate and understand each other. But, what would happen if pragmatics is not available? According to linguists and other specialized figures "Pragmatics acts as the basis for all language interactions and contact. It is a key feature to the understanding of language and the responses that follow this. Therefore, without the function of pragmatics, there would be very little understanding of intention and meaning" (AllAboutLinguistics.com).

It is worthy to mention that in spite of having people defending pragmatics, there are some others who criticize it. The table below shows both perspectives.

\begin{tabular}{|l|l|}
\hline \multicolumn{1}{|c|}{ Support } & \multicolumn{1}{c|}{ Criticism } \\
\hline $\begin{array}{l}\text { The study of speech acts has illuminated } \\
\text { social language interactions }\end{array}$ & It does not have a clear-cut focus \\
\hline $\begin{array}{l}\text { It covers things that semantics has } \\
\text { overlooked }\end{array}$ & Its principles are vague and fuzzy \\
\hline $\begin{array}{l}\text { It can help inform strategies for teaching } \\
\text { language }\end{array}$ & $\begin{array}{l}\text { It is redundant - semantics already covers } \\
\text { the territory adequately }\end{array}$ \\
\hline $\begin{array}{l}\text { It has given new insights into } \\
\text { understanding literature }\end{array}$ & $\begin{array}{l}\text { Look at meaning only from a novel } \\
\text { viewpoint }\end{array}$ \\
\hline $\begin{array}{l}\text { The theory of the cooperative principle } \\
\text { and politeness principle have provided } \\
\text { insights into person to person interactions }\end{array}$ & \\
\hline
\end{tabular}

Developing comprehension, analysis and writing skills 
Linguistically, it is highly essential for IGCSE students to develop their comprehension, analysis, and writing skills as well as the ability of metacognitive awareness of coming across some idioms and expressions used figuratively (figurative language) in texts and passages in the IGCSE Student Book and Exams which are needed to be figured out, interpreted and analysed. This would be perceived when students conceive their thought processes, in the sense they are practising megacognitive task which Martinez (2006) calls "monitoring and control of thought", while others call it "thinking about thinking" (p.694). This tool is extremely sturdy for learners."Metacognitive awareness must be introduced to students and be embedded within assignments. These types of assignments allow students to find rich metaphoric correspondences in ordinary experiences and elements" (James, 2002. p.32).

Practice to develop the comprehension skills, IGCSE students are required to do two fold tasks: skimming and scanning a text. Initially, to deal with the former, a student needs to read a text or a passage quickly focusing on spotting the main idea in each paragraph, whereas in the latter the student must read the text/passage carefully and deeply in order to do the annotation process; underline the keywords such as the literary devices and figuring out the wh-points such as names, reasons, numbers, times and dates. Therefore, the student must write notes and not full sentences and no need for a lot of details because this may waste time and result in wrong or unnecessary answers, and in the exam this will definitely affect the student's grading. Furthermore, the student has to avoid the copy-paste act and use his/her own words or to do quotation or paraphrasing process instead. In order for the student to boost and build up his/her linguistic knowledge, he/she is required to regularly learn new strong vocabulary and idioms which consequently make the student easily capable to learn the explicit (obvious) and implicit (implied/suggest) meaning. Accordingly, the student will be able to analyse, evaluate and develop facts, opinions and ideas as well as demonstrating good understanding of how authors touch the audience and being effective.

Now, we come to writing. Writing is a process consists of various phases. It begins with the planning phase and ends with the publishing (final copy) phase. In the directed writing, students have to consider various aspects, such as content (what to write about), the type of register (voice/appropriate style), audience (whom writing to), purpose (to describe, inform, persuade, advise, etc.), and format (type of writing, e.g. report, news article, feature article, speech, interview, summary, letter, blog, etc.). All these aspects should be available in the head of IGCSE student in this stage which is called the planning phase. Generally speaking, the writing process should go through the following stages: pre-writing, drafting, editing, revising and publishing. In the pre-writing/input stage, the student starts to determine what to write and the form in which to be written. It is brainstorming stage in which students practice generating as much ideas as they can. Crystal (2006:127) confirms that "we organize our thoughts and prepare an outline of what we want to say. Even the shortest of messages requires a moment or two of planning." The next stage is called the first draft writing. In this stage no perfect writing is expected. This stage is of just discovering ideas and the learner's writing might be changed later on in the process. If it happened that a learner missed some essential thoughts to be included in the first draft, he could include them in a later draft. "Two sets of skills are 
involved in this stage. The first is called compositional skills wherein the students practice choosing the right words, sentences, and text structures as well as setting them out in a way that expresses the intended ideas. The second is called transitional skills usually involved in translating the words and sentences in the student's head into marks on the page or screen. These skills include handwriting, spelling and punctuation" (Al Jumaily, 2015, p.31). Eyres (2007) assures that "the value of the first draft is paramount; it is the clay from which the final draft is fashioned" (p. 211). In this stage students need not to spend a lot of time since it is an initial draft and owing to the fact that the real work still entails modification and development through the successive draft stages. The next stage is the writing of the second draft which comprises two activities: revision and proofreading. In the revision process, the learner can make changes in the content as well as checking grammar, spelling and punctuation and pay attention to ideas and organization. Here, students are going to add, remove, and re-ordering words to improve the writing quality and check the strong and weak points in their writings. However, the proofreading stage is the step before publishing in which students make sure of the structure and content of their writings through checking, deleting, substituting and reordering. Eventually, the final draft is written or typed in order to be published.

\section{Brief guidance for writing an article}

If a student tries to write an article of 4 paragraphs, for example, the first is the opening paragraph of the writing. This paragraph is really introduces the reader to the writing or describes the setting in case of writing a story. It is pretty essential for the student to learn that each paragraph must have a topic sentence. The topic sentence of the second paragraph ought to be related to the task given in the question in order to help the student to write properly. The topic sentence of the third paragraph is meant to develop or support the main idea, whereas the ending paragraph (paragraph 4) must contain the conclusion. Thus, each paragraph has to have only one idea. Students must remember that a good plan results in a good writing, but usually the number of paragraphs defined and determined according to the question (direction) or depending on the ideas a writer wants to include. It is, indeed, through keywording the question, the number of the paragraphs determined. Usually, students practise the brainstorming process before starting to write the first draft.

In order to broaden IGCSE students' linguistic and literary skills about figurative language, two sample lessons have been tailored aiming to assist students alongside teachers to achieve their mission successfully.

\section{Lesson One}

This lesson is organized to let students practise first and later being assessed. They are going to practise figuring out and explaining the meaning of the commonplace idioms and expressions, in addition to show their understanding through pointing out the difference between literal and nonliteral (figurative) meanings of the idioms. 
Subject: English / Grade 9 / Participants: students / Materials: Student Book, worksheets, computers, internet, videos / Instructive time: 90 minutes / Assessment tools: discussion \& grading / Lesson plan: General lesson plan / Learning objectives: the outcome is students being able to figure out and explain the meaning of idioms and expressions alongside with determining the literal and nonliteral meanings of idioms.

Linguistic knowledge needed: students must have prior knowledge of:

- how to spot and explain the meaning of idioms (from previous years),

- how to differentiate between literal and nonliteral meanings of words,

- how to identify and explain the meaning of literary technique used,

- how to read poetry properly according to the reading technique,

- how to work in a group or in pair collaboratively.

Warming up guiding questions: in order to refresh students' minds, the following warming up questions designed:

- Is there a difference between literal and figurative language? If yes, what is that?

- Do you know idioms?

- What purpose does an idiom have?

- Do you know some examples of commonplace idioms?

Way of presentation: below is the procedure/method of teaching:

1. Initially, the teacher needs to have a warm-up starter written on board containing some nonliteral English while students need to do the brainstorming process through working in pairs.

2. Bring students back to be a whole class in order for students to provide their answers in order to discuss some of them.

3. Now, start your normal lesson explaining more about figurative language through giving students further information about literal and nonliteral language and through the use of some idioms and expressions supported by a short video if possible. The teacher can make use of some videos from the website: WatchKnowLearn.org. This website is highly supportive and useful. The video should be performed by students in which they use and discuss literal as well as nonliteral language. The teacher can pause the video when necessary to discuss and assess how far the students understood the subject matter as well as providing some explanation about the idioms used. In order for the students to understand the idioms fully, the teacher needs to use the board to illustrate and explain the figurative meanings after watching the video.

4. Next time after reading literary texts or poetry, ask students to spot and analyse the figurative language used. Try to circulate among students to provide your remarks when necessary.

5. To do homework assignment, the teacher asks his/her students to write a text of 250-350 words in which he/she uses figurative language to entertain the audience 
through effective writing style. The teacher needs to give the students at least 48 hours to achieve the assignment. This practice must take place regularly.

6. After checking, providing remarks and grading students' answers, try to choose some good writings to be discussed in the class in order to motivate and encourage other students, mainly those who are struggling. Let students always learn from each other, and don't forget it is student-centred process.

\section{Lesson Two}

This lesson consists of 4 stages. They are as follows:

1. Start introducing your students to some new literary devices, such as literary techniques and literary elements. Try to provide some examples of explicit and implicit meaning because this is the most principal method of teaching figurative language. The teacher's main goals at this stage that students have the ability to identify the literary elements, such as metaphor, simile, hyperbole, alliteration, assonance, oxymoron, paradox, personification, analogy, onomatopoeia, imagery language, etc. Accordingly, the teacher writes some phrases on the board and asks students to tell the type of figurative language in each phrase according to the context in which each is used. A teacher can also use labelled coloured sheets of various literary elements and ask students to do the sorting game activity to identify the nonliteral language out of the context according to their linguistic environment. Students will definitely enjoy doing this activity if it is designed as a kind of competition among groups. The teacher can display the video taken from the website One Stop Teacher Shop and available on the link:https://www.facebook.com/1StopTeacherShop/videos/figurativelanguage/1094883080902023/to achieve this activity successfully.

2. Now, let students practise reading texts and using context clues to figure out the nonliteral meaning through their analytical thinking skills. It is recommended that the teacher addresses his/her students with some questions to refresh their memories after reading a text; questions about figurative/implicit meaning, why writers use figurative language and what this use adds to the quality of writing, and in which way the writer uses the literary elements to make the text more effective.

3. Since poetry is immensely rich with figurative language, as a teacher try to teach your students this language through poetry in which a student must actively use context clues process to figure out the context-dependent meanings. This will definitely sharpen your students' analytical thinking skills. Cambridge IGCSE Student Book is rich with poetry. Thus, ask your students to read a poem to spot the figurative idioms used and then to analyse their meanings, and why the poet uses this technique/diction. Ask students to tell what this style adds to the poem.

4. Since it is a student-centred process, students need to get the opportunity to work independently dealing with figurative language. Students must have enormous exposure to figurative language to boost their knowledge about it, and consequently use it when they write. 


\section{Findings and Discussion}

The results arrived at reflect that the strategy and plan as well as the procedure followed were proper and accurate. Students began to go beyond the box when using the context clues technique to spot the unconventional or contextual meaning which ultimately helped them a lot to properly demonstrate their analytical thinking and writing skills. A lot of progress in the use of figurative language was noticed. At the end of the course, students' megacognitive skills highly improved and turned the students optimistic, after being frustrated at the beginning, to achieve the IGCSE Exams confidently. Their performance right now compared to that at the beginning of the course is immensely different. As a teacher, I found my students became overwhelmingly motivated and eager to practise/learn. The major factor responsible for this success is the friendly communication and ties with the students. It is academically and according to educational psychology, when students love their teacher, they consequently love his/her subject. Checking and providing remarks regularly and asking the students to take them on board led to great improvement in the students' performance when they were reading texts to comprehend and analyse which was happening at least three times a week as well as doing homework writing assignments twice a week. This type of exposure to figurative language highly developed students' linguistic knowledge related to the nonliteral language. But still and observed that students whose parents were using English at home to communicate with each other were faster to master the subject than those whose parents were using languages other than English at home. Thus, students must encounter figurative language in both oral and written expressions on a daily base whether at home or school, and the introduction of figurative language instruction must start as early as possible. Like Boers (2000), the researcher believes that language learners are compelled to deal with figurative discourse at various stages of their learning (p.553). Language learners are required to develop their abilities to understand and use figurative language through years of practice as they mature.

\section{Conclusions and Suggestions}

It has been found that figurative language is powerful and hugely used whether by authors or people in their daily conversations because it allows both writers and speakers to go beyond the literal meaning. On the personal level after teaching this subject, a remarkable improvement noticed in my students' analytical thinking skills mainly when they took my remarks on board and put in practice the megacognitive aspect (monitoring and control of thought). At the beginning some students were struggling and could not interpret multiple meaning expressions, but with proper exposure and immersion alongside providing guidance about how to realize and understand the context clues, things grew better. Teaching various grades, it has been noticed that the age factor plays a major role in understanding figurative language. Furthermore, since parents are not native speakers and English is not used at home among students' family members, students could not develop their linguistic knowledge about nonliteral idioms. To conclude, the study has arrived at the fact that this type of language people use regularly when speaking and writing, and hopefully students could use it in their learning and carry it with them when reading to comprehend and analyse or when they write. It is recommended and advised that IGCSE students are immensely exposed to a variety of literary 
texts wherein nonliteral language used. In the light of the results arrived at, it is suggested and recommended that Cambridge IGCSE teachers, since parents are not native speakers to help their children to learn nonliteral idioms, try to put more efforts, utilize the results of this study and find other ways to prepare their students for the IGCSE Exams. It is believed that this study could be the base for further future studies tackle figurative language used in the Cambridge IGCSE Textbooks.

\section{Conflict of Interest}

The author declares no conflict of interest during the preparation and submission of this paper.

Funding

The author solely funded and financed this study.

\section{References}

Akmajian, A., Demers, R. A., Farmer, A. K., \& Harnish, R. M. (2001). An introduction to language and communication. In Library of Congress Cataloging-in-Publication Data.

Al-Jumaily, S. (2015). Improving my students' writing skill: An intensive course for ESL learners by using process-approach to writing with the assistance of computer word processor. International Journal of English Language Teaching, 2(1), 29-35.

AllAboutLinguistics. What is pragmatics? (n.d.). Retrieved January 27, 2021, from https://all-about-linguistics.group.shef.ac.uk/branches-of-linguistics/pragmatics/whatis-pragmatics/

Bach, K. (2001a). Speaking Loosely: Sentence Nonliterality. Journal of Midwest Studies in Philosophy 25, 249-263.

Boers, F. (2000). Metaphor awareness and vocabulary retention. Applied linguistics, 21(4), 553-571.

Charteris-Black, J. (2002). Second Language Proficiency: A Comparative Study of Malay and English. Applied Linguistics, 23, 104-133.

Cole, P. (ed.). (1981). Radical Pragmatics. New York: Academic Press.

Crystal, D. (1987). The Cambridge Encyclopaedia of Language. Cambridge, USA:

Cambridge University press.

(1987). A Dictionary of Linguistics and Phonetics. Oxford, Basil: Blackwell, Ltd. (2006). How Language Works. London: Penguin Books Ltd.

Eyres, I. (2007). English for Primary and Early Years. Los Angeles: Sage Publication.

Graves, M. F., Juel, C., \& Graves, B. B. (2007). Teaching Reading In The 21st Century (4th ed.). Boston: Allyn\& Bacon.

English Worksheets Land Common Core Aligned Language Arts Worksheets. (n.d.).

Retrieved January 27, 2021, from

https://www.englishworksheetsland.com/grade3/22literal.html

Gray, M. C. (1984). A Dictionary of Literal Terms. Burnt Mill: Longman York Press. 
Holman, C. and Harmon, W. (1986).A Handbook to Literature (5th Ed). New York: Macmilla.

James, P. (2002). Ideas in Practice: Fostering Metaphoric Thinking. Journal of Developmental Education, 25, 26-33.

Kadmon, N.(2001). Formal Pragmatics: Semantics, Pragmatics, Presupposition, and Focus. Oxford: Blackwell.

Katz, J. (1977). Propositional Structure and Illocutionary Force., New York: Crowell.

Lauren, S. and Johnson B. (1997). Encyclopedia Americana. New York: New Field Publications.

Martinez, M. E. (2006). What is metacognition? Phi Delta Kappan Journal, 87, 696-699.

Nippold, M. A., \& Taylor, C. L. (2002). Judgments of Idiom Familiarity and Transparency: A Comparison of Children and Adolescents. Journal of Speech, Language, and Hearing Research, 45, 384-391.

Ortony, A. (1984). Understanding figurative language. In P.D. Pearson (Ed.), Handbook Of Reading Research (Vol. 1, pp. 453-470). New York: Longman.

Random House Dictionary. (1983). The Unbridged Edition, Random House: New York.

Recanati, F.(2004). Literal Meaning. Cambridge:Cambridge University Press.

Thomas, J. (1995). Meaning in Interaction: An Introduction to Pragmatics. London: Longman Tompkins, G. E. (2002). Literacy for the 21st Century (3rd Ed.). Upper Saddle River, NJ: Prentice Hall. 